\title{
Joint inversion of strong motion and geodetic data for the source process of the 2003 Tokachi-oki, Hokkaido, earthquake
}

\author{
Kazuki Koketsu ${ }^{1}$, Kazuhito Hikima ${ }^{1}$, Shin'ichi Miyazaki ${ }^{1,2}$ and Satoshi Ide ${ }^{3}$ \\ ${ }^{1}$ Earthquake Research Institute, University of Tokyo, 1-1-1 Yayoi, Bunkyo-ku, Tokyo 113-0032, Japan \\ ${ }^{2}$ Department of Geophysics, Stanford University, 397 Panama Mall, Standford, CA 94305, USA \\ ${ }^{3}$ Department of Earth and Planetary Sciences, University of Tokyo, 7-3-1 Hongo, Bunkyo-ku, Tokyo 113-0033, Japan
}

(Received January 6, 2004; Revised March 2, 2004; Accepted March 2, 2004)

\begin{abstract}
The strong motion and geodetic data were individually inverted for the source process of the 2003 Tokachi-oki, Hokkaido, earthquake with a hypocenter $25 \mathrm{~km}$ deep and a fault plane above the subducting Pacific slab. Both the results show a simple slip distribution with a single major asperity, but the strong motion inversion may include a trade-off between slip location and rupture time and the geodetic inversion does not have sufficient resolution for far slips. We then carred out a joint inversion of the two datasets in order to overcome these weaknesses of the single dataset inversions. The resultant slip distribution still retains the simple pattern and has a seismic moment of $2.2 \times 10^{21} \mathrm{~N} \cdot \mathrm{m}\left(M_{\mathrm{w}} 8.2\right)$. The asperity, with a peak slip of $7.1 \mathrm{~m}$, is located in the center of the fault plane $50 \mathrm{~km}$ away from the hypocenter in the down-dip direction. The slip rate functions on subfaults around the hypocenter and asperity indicate that the rupture propagated with a supershear speed on the upper part of the fault plane and slowed down to $100-90 \%$ of the $S$-wave velocity on the middle and lower parts. These simple slip patterns and near-supershear rupture may imply the maturity of the Hokkaido subduction zone around the source region.
\end{abstract}

Key words: Source process, joint inversion, strong motion data, geodetic data.

\section{Introduction}

A great earthquake with a JMA magnitude $\left(M_{\mathrm{JMA}}\right)$ of 8.0 occurred at 4:50 a.m. on September 26, 2003 (JST $=$ UT +9 hours) off the Tokachi district of Hokkaido, northern Japan (JMA: Japan Meteorological Agency, 2003). This Tokachioki earthquake was the largest event around the Japan islands after the $M_{\mathrm{JMA}} 8.2$ Hokkaido Toho-oki earthquake in 1994. JMA (2003) located its epicenter above the subducting Pacific slab (41 ${ }^{\circ} 46.78^{\prime} \mathrm{N}, 144^{\circ} 4.71$ 'E; Fig. 1). The focal mechanism determined by Yamanaka and Kikuchi (2003) indicated low-angle reverse faulting in the direction of subduction, therefore the earthquake was an event thrusting along the upper boundary of the Pacific slab.

Yamanaka and Kikuchi (2003) also carried out a waveform inversion of teleseismic data and obtained the best fit with a hypocentral depth of $25 \mathrm{~km}$. This depth is consistent with the slab surface (Katsumata et al., 2003; Earthquake Research Committee, 2003) at the JMA epicenter as shown in Fig 1, so that we will adopt it as the depth of the rupture initiation point. We will also adopt the strike $\left(230^{\circ}\right.$ from the north) and dip angle $\left(20^{\circ}\right)$ in the above-mentioned focal solution, for the geometry of a fault plane.

\section{Data and Method}

Among several nation-wide seismic arrays, KiK-net (Aoi et al., 2000) is the best for our study, since it consists of borehole instruments as well as surface ones at all of the sta-

Copy right(C) The Society of Geomagnetism and Earth, Planetary and Space Sciences (SGEPSS); The Seismological Society of Japan; The Volcanological Society of Japan; The Geodetic Society of Japan; The Japanese Society for Planetary Sciences; TERRAPUB tions. The former is installed in a borehole $100 \mathrm{~m}$ or more deep, so that seismograms are influenced little by shallow soil conditions. Figure 2 compares the borehole and surface seismograms at the station HDKH04. The bottom trace was observed at a station of K-NET (Kinoshita, 1998) close to HDKH04. High-frequency reverberation in the soil contaminates the surface motions at both the KiK-net and K-NET stations, but the borehole seismogram is almost free from this contamination. Therefore, we used three-component borehole seismograms at the eleven KiK-net stations, plotted with solid triangles in Fig. 3. The seismograms were recorded by accelerometers, so they were numerically integrated to obtain velocity waveforms. The resultant velocities were filtered out with a pass band of $0.05-0.2 \mathrm{~Hz}$, and resampled with an interval of $0.5 \mathrm{~s}$.

Miyazaki and Kato (2003) derived coseismic displacements from GPS data at the stations of GEONET (Geographical Survey Institute, 1998) in Fig. 3. They calculated the average coordinates for September 2 to 24 and those for one hour between the mainshock and largest aftershock. The difference between these coordinates will be used as horizontal displacements due only to the mainshock.

The strong motion and geodetic data mentioned above will be inverted using the method of Yoshida et al. (1996) based on the formulation of multiple time windows (e.g., Olson and Apsel, 1982). We assumed the $120 \times 100 \mathrm{~km}^{2}$ fault plane in Fig. 1 and divided it into 10 by $10 \mathrm{~km}$ subfaults with point slips at their centers. The time function of slip is expressed by a superposition of ramp functions with a rise time of $1 \mathrm{~s}$ in the 15 time windows. Since Yamanaka and Kikuchi (2003) have already found the slip orientation to be reverse faulting 


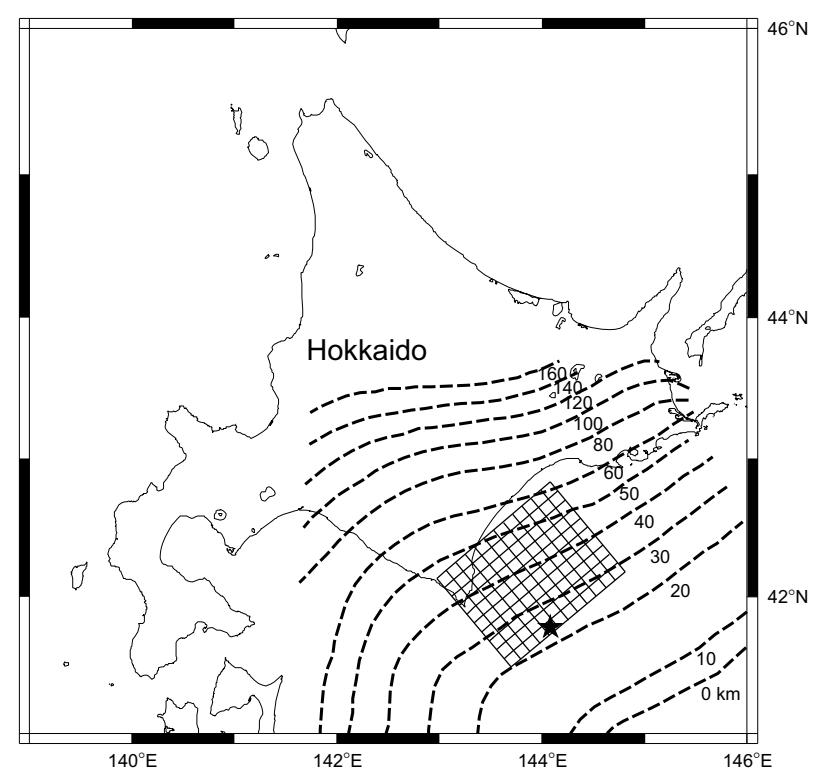

Fig. 1. The epicenter of the 2003 Tokachi-oki earthquake determined by JMA (solid star). The dashed depth contours in km represent the upper boundary of the Pacific slab subducting under Hokkaido (Katsumata et al., 2003; Earthquake Research Committee, 2003).

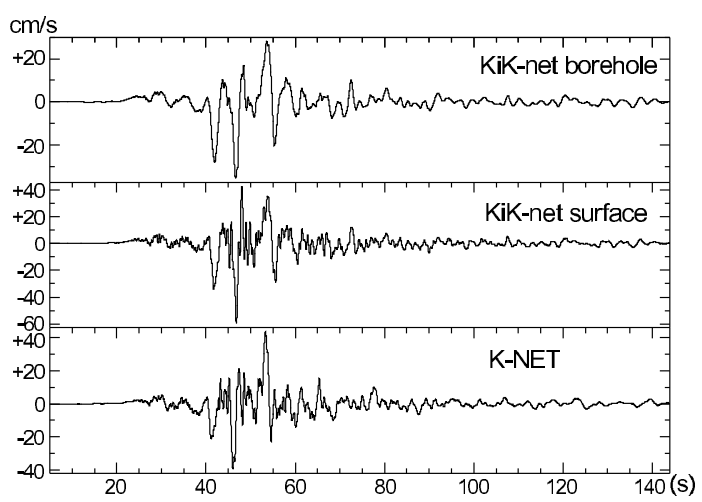

Fig. 2. Borehole and surface velocity seismograms at HDKH04 of KiK-net. The seismogram observed at a K-NET station close to HDKH04 is also shown for comparison.

with a rake angle of $109^{\circ}$, the slip vector on a subfault is represented by a linear combination of two components in the directions of $90 \pm 45^{\circ}$. We stabilized the inversion by imposing smoothness constraints for the discrete Laplacian in space and time:

$$
\begin{aligned}
\nabla^{2} X_{m n l} & =X_{m+1, n, l}+X_{m, n+1, l}+X_{m, n, l+1} \\
& +X_{m-1, n, l}+X_{m, n-1, l}+X_{m, n, l-1}-6 X_{m, n, l}
\end{aligned}
$$

where $X_{m n l}$ is the slip on the $m n$-th subfault in the $l$ th time window. $X_{m, n, l+1}-X_{m, n, l}$ and $X_{m, n, l-1}-X_{m, n, l}$ in (1) perform temporal smoothing and relax the overparameterization, which may arise from an inversion with so many time functions as in this study. We determined the appropriate weights of the constraints relative to the data misfits referring to the Akaike Bayesian information criterion (Akaike, 1980).

We used the reflectivity method of Kohketsu (1985) with the velocity structure in Table 1 for the Green's functions, and extended it to buried receivers to calculate synthetic

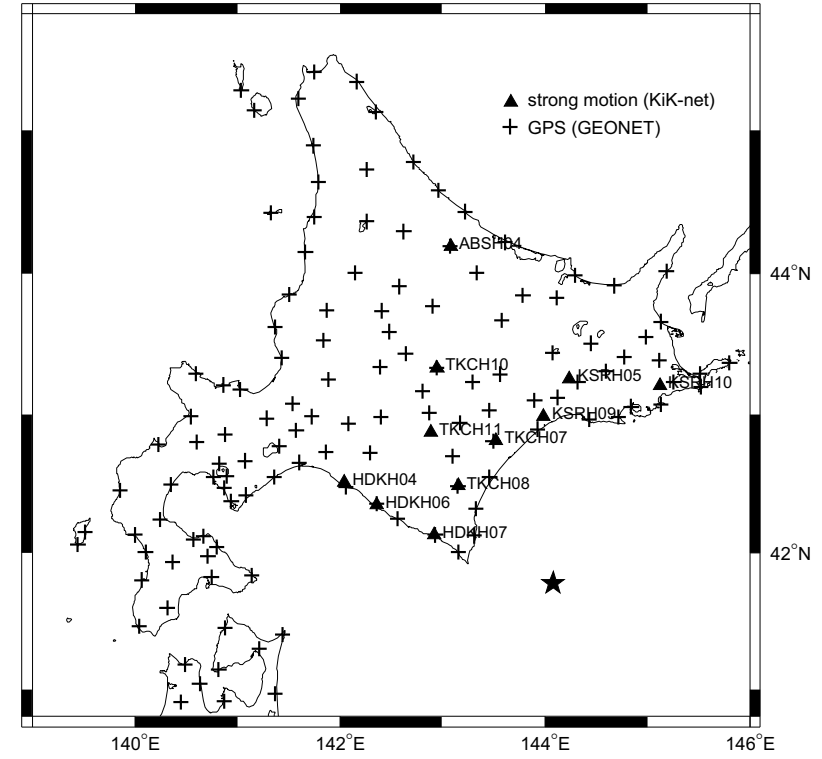

Fig. 3. KiK-net stations (solid triangles) and GEONET stations (crosses) where the used data were observed.

Table 1. Velocity structure.

\begin{tabular}{ccc}
\hline thickness $(\mathrm{km})$ & $V_{\mathrm{P}}(\mathrm{km} / \mathrm{s})$ & $V_{\mathrm{S}}(\mathrm{km} / \mathrm{s})$ \\
\hline 1.5 & varying with stations \\
2.5 & 5.8 & 3.3 \\
10 & 6.1 & 3.5 \\
6 & 6.5 & 3.7 \\
8 & 7.0 & 4.0 \\
32 & 7.7 & 4.4 \\
$\infty$ & 8.0 & 4.6 \\
\hline
\end{tabular}

borehole seismograms. We represent here the elements of the propagator matrix product for the part of the structure above the receiver as $G_{11}, G_{12}, G_{21}, G_{22}$. We can now relate the Fourier-Bessel transforms of radial $U$, tangential $V$ and vertical motions $W$ at the receiver to the transformed surface motions $U_{0}, V_{0}$ and $W_{0}$ as

$$
\begin{aligned}
U & =G_{11} U_{0}+G_{12} W_{0} \\
V & =G_{11}^{\prime} V_{0} \\
W & =G_{21} U_{0}+G_{22} W_{0},
\end{aligned}
$$

where $G_{i j}$ with or without a prime denotes an element for the $\mathrm{SH}$ wavefield or the $P-S V$ wavefield. Equation (2) enables us to calculate borehole motions from surface motions by the original method.

This method works only for one-dimensionally stratified structures, but the stations are located in various site conditions. Therefore, we use a set of velocity structures introducing a common part below a depth of $1.5 \mathrm{~km}$ as shown in Table 1. This part was determined based on Iwasaki et al. (1989), and the varying shallower part was modeled by using the results of velocity logging at the KiK-net stations and others. To reduce possible artifacts due to the incompleteness of the velocity structure, scalar time shifts were added to the Green's functions, and their values were also determined by the inversion. For geodetic Green's functions we 


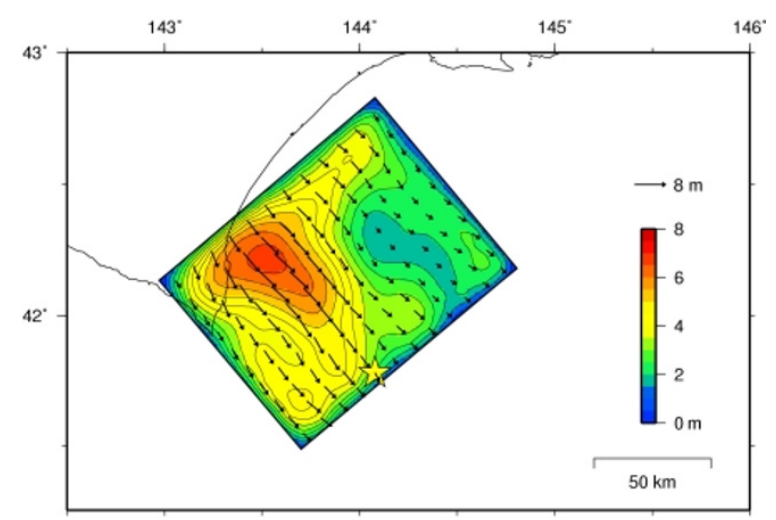

Fig. 4. Slip distribution recovered by the strong motion inversion $\left(M_{0}\right.$ : $\left.2.5 \times 10^{21} \mathrm{~N} \cdot \mathrm{m}, M_{\mathrm{w}}: 8.2\right)$. The arrows indicate the slip vectors of the hanging wall relative to the foot wall.

assumed a semi-infinite medium with a Poisson ratio of $1 / 4$, since the velocity structure does not affect static displacements so much as shown in e.g. Koketsu et al. (2003).

\section{Single Dataset Inversions}

We first carried out an inversion of the strong motion dataset alone. All the waveforms were equally weighted. We assumed the rupture to start from the hypocenter and the first time window to propagate with a velocity of $3.6 \mathrm{~km} / \mathrm{s}$. This propagation velocity corresponds to $82 \%$ of the $S$-wave velocity $(4.4 \mathrm{~km} / \mathrm{s})$ on most of the fault plane. Figure 4 shows the slip distribution inferred from this strong motion inversion. The synthetic seismograms for the inversion result agree well with the observed ones as shown in Fig. 5. The stations KSRH05 and HDKH04 are located in large sedimentary basins, so that well-developed surface waves contaminate the later portions of their seismograms. We note that these portions were already removed from the dataset. An asperity, that is a zone of large slips, was recovered with a peak slip of $6.7 \mathrm{~m}$ in the north-western part of the fault plane. It is located $70 \mathrm{~km}$ away from the hypocenter in the dip direction. The total seismic moment of this solution was $2.5 \times 10^{21} \mathrm{~N} \cdot \mathrm{m}$, which corresponds to a moment magnitude $\left(M_{\mathrm{w}}\right)$ of 8.2. An average delay of $1.6 \mathrm{~s}$ was obtained for the seismograms observed at the western stations HKDH04, 06 and 07 , while time advances of $1.1 \mathrm{~s}$ and $0.7 \mathrm{~s}$ were recovered for the TKC and KSR stations in eastern Hokkaido, respectively. These time shifts are consistent with the 3-D crustal structure in this region (Murai et al., 2003).

Next, we inverted the horizontal displacements at the 127 GPS stations shown in Fig. 3. The resultant slip distribution in Fig. 6 shows similar features to those in the strong motion inversion. There exists one major asperity with a peak slip of $6.8 \mathrm{~m}$ and it is again located in the dip direction from the hypocenter. However, the GPS solution shows stronger slip on the far part of the fault plane and the total seismic moment $\left(2.0 \times 10^{21} \mathrm{~N} \cdot \mathrm{m}, M_{\mathrm{w}} 8.1\right)$ is a little smaller than the previous result, though the synthetic displacements agree well with the observations in Fig. 7. Since similar behavior of a GPS solution was found by Jónsson et al. (2002) for the 1999 Hector Mine earthquake, these differences may be due to the low resolving power of GPS data for far slips. Nevertheless, a strong motion inversion intrinsically has a

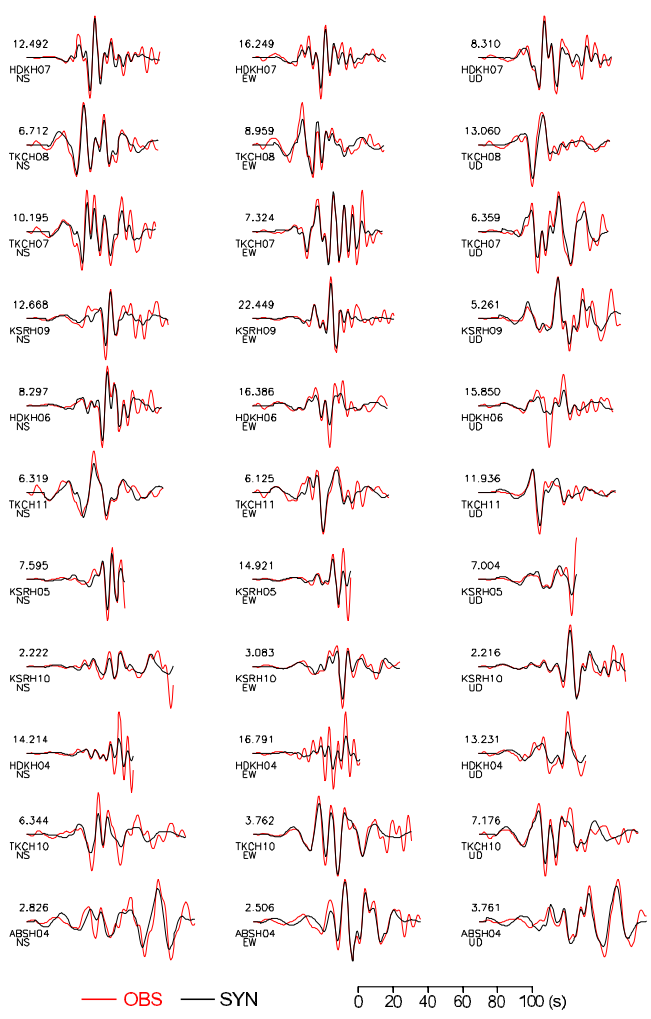

Fig. 5. Comparison of the observed velocity waveforms (red traces) and synthetic waveforms for the solution of the strong motion inversion (black traces).

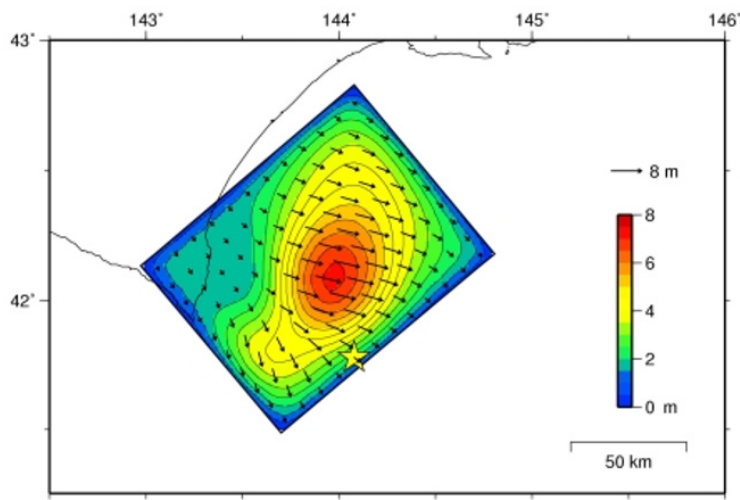

Fig. 6. Slip distribution recovered by the geodetic inversion $\left(M_{0}: 2.0 \times\right.$ $\left.10^{21} \mathrm{~N} \cdot \mathrm{m}, M_{\mathrm{W}}: 8.1\right)$.

trade-off between slip location and rupture time, and GPS data can ease it by constraining the locations of near slips. Finally, we carried out a joint inversion of the strong motion and GPS data.

\section{Joint Inversion}

We simultaneously inverted the strong motion and geodetic data all together. The resultant slip distribution in Fig. 8 appears to be an average of the two solutions of the single dataset inversions in Figs. 4 and 6. The seismic moment (2.2 $\times 10^{21} \mathrm{~N} \cdot \mathrm{m}, M_{\mathrm{w}} 8.2$ ) is also an average of those from the single dataset inversions. The major asperity with a peak slip of $7.1 \mathrm{~m}$ is now located in the center of the fault plane $50 \mathrm{~km}$ away from the hypocenter in the dip direction. The synthetic seismograms are still in good agreement with the observed 


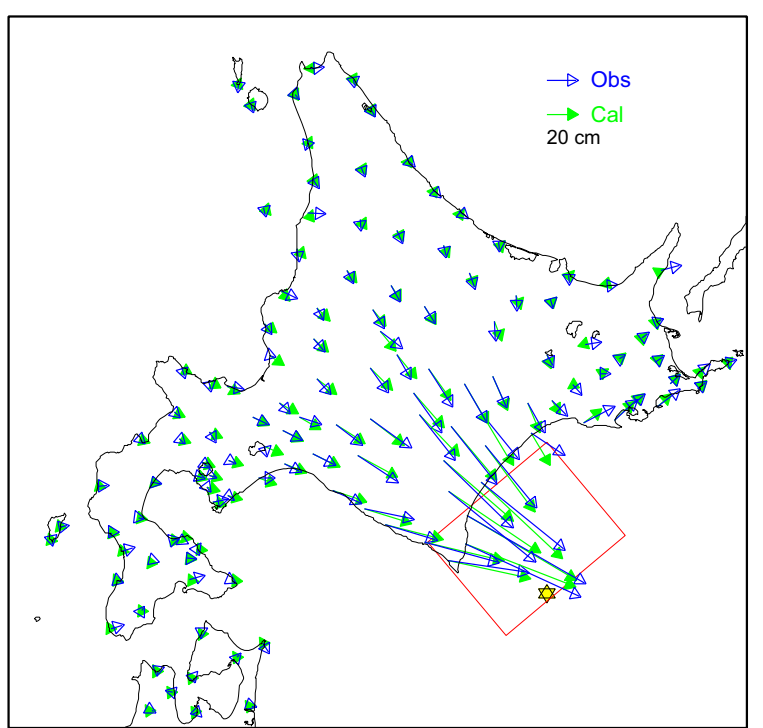

Fig. 7. Comparison of the observed displacements (green arrows) and synthetic displacements for the solution of the geodetic inversion (blue arrows). The red box and star indicate the fault plane and rupture initiation point, respectively.

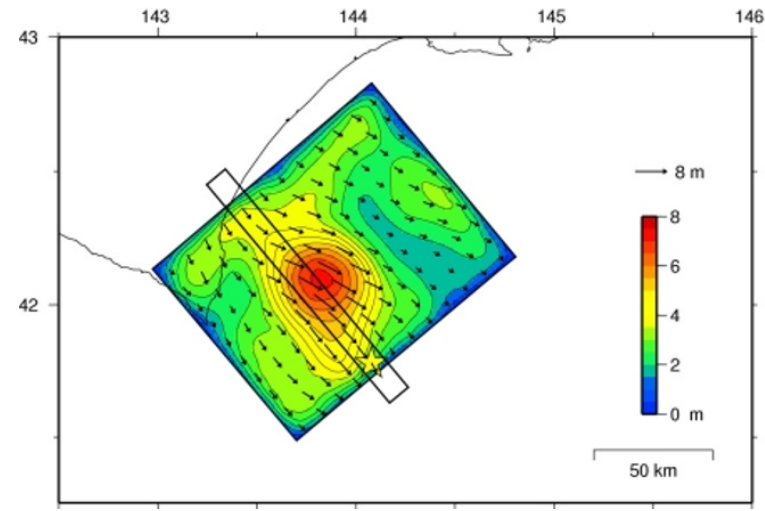

Fig. 8. Slip distribution recovered by the joint inversion $\left(M_{0}: 2.2 \times 10^{21}\right.$ $\mathrm{N} \cdot \mathrm{m}, M_{\mathrm{w}}: 8.2$ ). The slip rate functions of the subfaults in the black rectangle will be shown in Fig. 12 .

seismograms as shown in Fig. 9. Figure 10 compares the observed geodetic data with displacements calculated for the joint inversion solution. The agreement is as good as in the result of the geodetic inversion, but a match to the displacements near the source region is a little degraded because of compromise in the joint inversion.

Figure 11 represents the growth of the rupture by showing the slip-rate distribution every $3 \mathrm{~s}$. The major asperity A propagates from the hypocenter to the northwest in the dip direction. In addition, we can identify two minor asperities in the snapshots. $b$ appears on the northeastern part of the fault plane at 21 to $36 \mathrm{~s}$ after the rupture initiation. Ide (2003) identified this asperity using ocean-bottom seismograms observed by JAMSTEC. The other, which is labeled $\mathrm{C}$ in Fig. 11, is initiated around the center of the fault plane after $A$ runs through this part. It then turns to the north approaching the lowermost corner of the fault plane.

There are ten subfaults in line between the hypocenter and the lower boundary of the fault plane. This line (black rectangle in Fig. 8) runs across the main part of the slip dis-

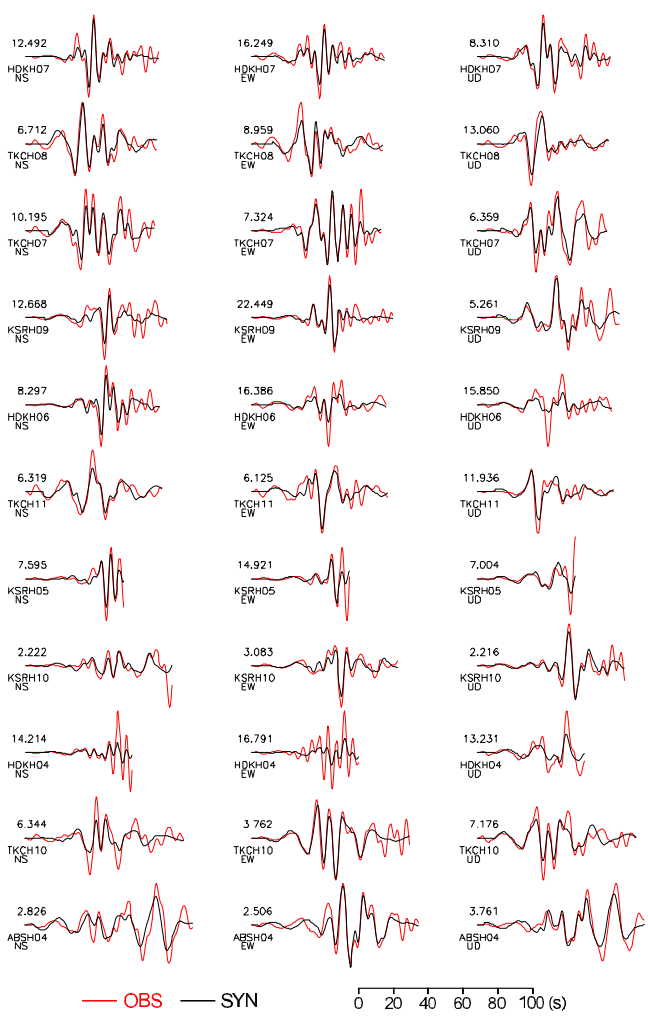

Fig. 9. Comparison of the observed velocity waveforms (red traces) and synthetic waveforms for the solution of the joint inversion (black traces).

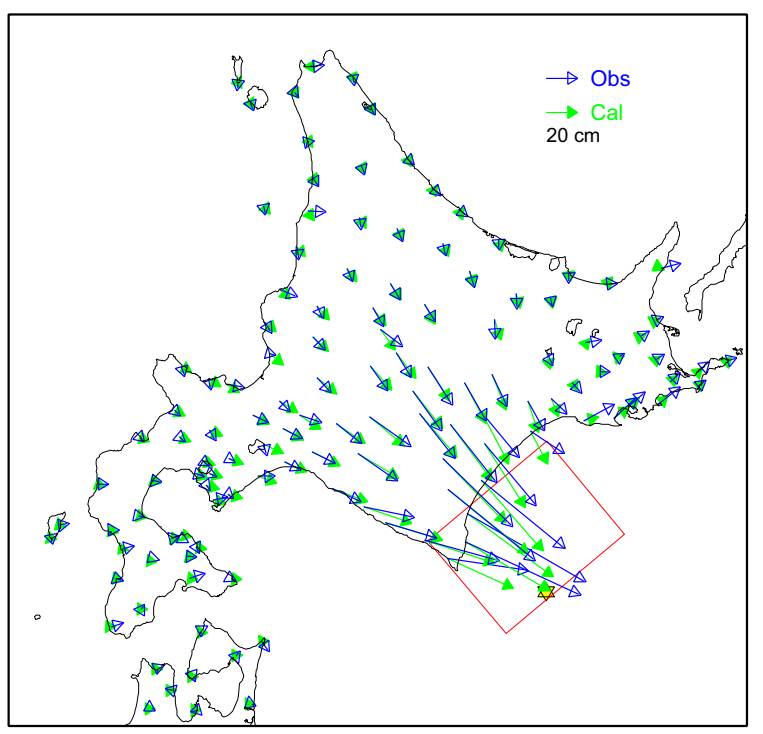

Fig. 10. Comparison of the observed displacements (green arrows) and synthetic displacements for the solution of the joint inversion (blue arrows). The red box and star denote the fault plane and rupture initiation point, respectively.

tribution including the major asperity, and so the slip rate functions (derivatives of slip histories) recovered in the subfaults along the line are displayed in Fig. 12 in order to represent the details of the rupture during the 2003 Tokachi-oki earthquake. As mentioned earlier, the slip history in each subfault is modeled with ramp functions in fifteen sequential time windows and a rise time of $1 \mathrm{~s}$. The first time window is assumed to propagate with a velocity of $3.6 \mathrm{~km} / \mathrm{s}$, but the slip rates in the first several windows are very small in the upper- 

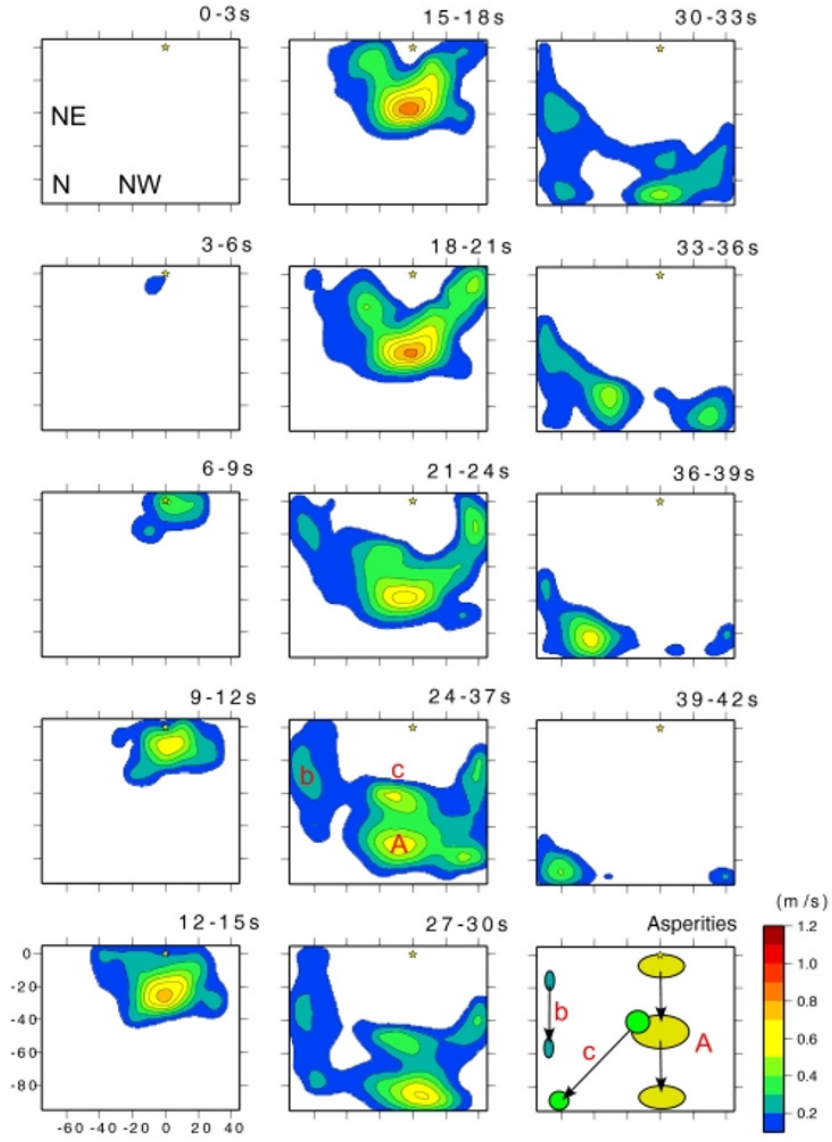

Fig. 11. Snapshots of the source process represented by the slip-rate distribution every $3 \mathrm{~s}$. The bottom-right panel schematically illustrates the progress of the asperities.

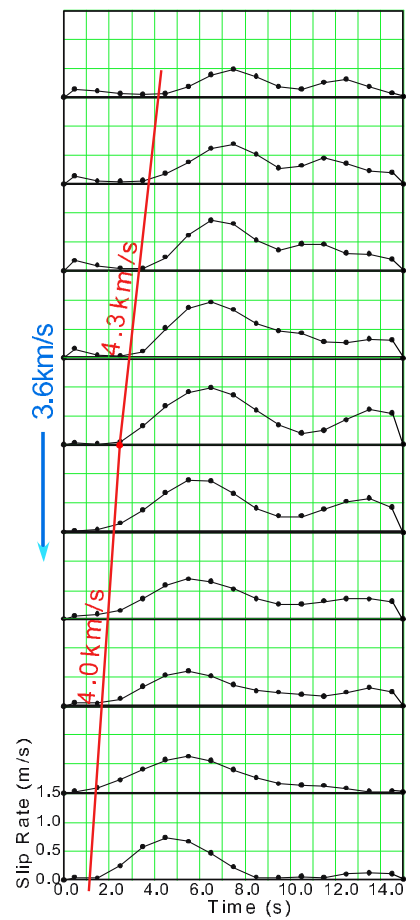

Fig. 12. Slip rate functions in the subfaults indicated in Fig. 8 with a black rectangle.

most subfault of the hypocenter, so that the rupture looks to be locked for about $5 \mathrm{~s}$ in the initial stage. The rupture prop-

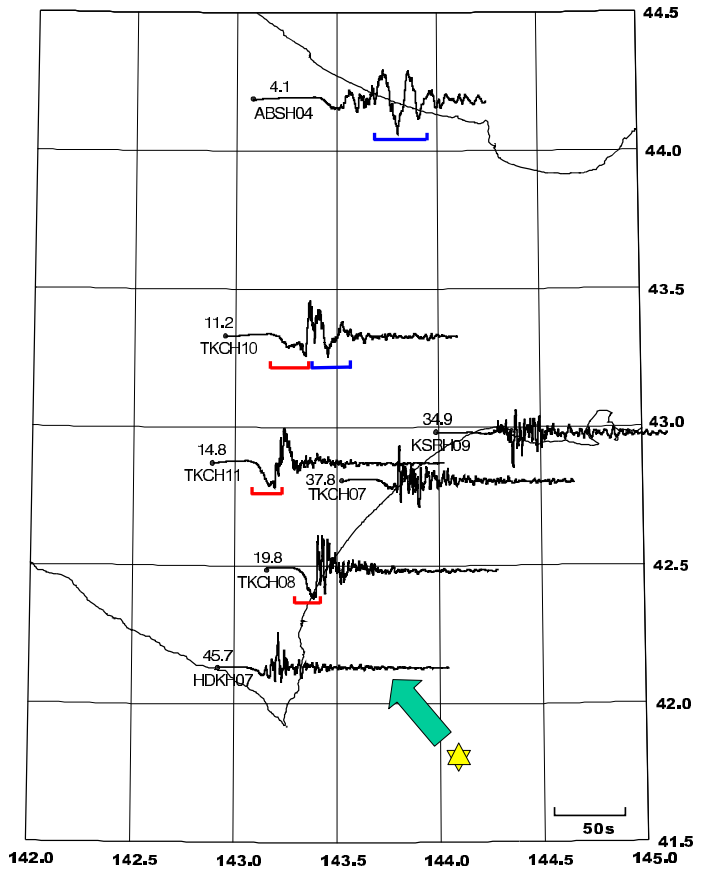

Fig. 13. Radial velocity seismograms observed at the stations in the north of the source region. The traces are normalized to their peak amplitudes. The star and arrow denote the epicenter and main rupture direction, respectively.

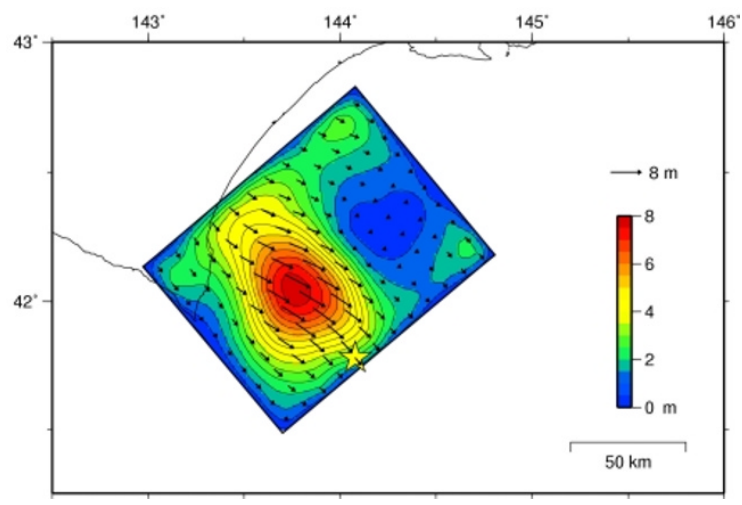

Fig. 14. Slip distribution by another joint inversion with ten time windows and a rise time of $2 \mathrm{~s}$.

agation is then accelerated to a velocity of $4.3 \mathrm{~km} / \mathrm{s}$, and it finally slows down to $4.0 \mathrm{~km} / \mathrm{s}$ as shown in Fig. 12. The slip rate functions in the center subfaults have two peaks, which indicate the major asperity $A$ and the minor asperity $c$.

The upper one and a half subfaults fall within the fifth layer of the velocity structure in Table 1 . As the $S$-wave velocity $\left(V_{s}\right)$ is $4.0 \mathrm{~km} / \mathrm{s}$ in this layer, the rupture velocity $\left(V_{r}\right)$ is higher than $V_{s}$. In other words, the fault rupture propagates at a 'supershear' speed in the zone around the hypocenter (Rosakis, 1999; Ide, 2003). $V_{r}$ is almost equal to $V_{s}$ in the middle of the fault plane, and it is reduced to $90 \%$ in the lower part. This supershear $\left(V_{r}>V_{s}\right)$ or nearsupershear $\left(V_{r} \sim V_{s}\right)$ situation results in directivity effects on $P$-waves and the near-field term, or those on $S$-waves, respectively. The effects are confirmed by the long-period pulses indicated by the red and blue brackets in the velocity seismograms at the stations in the north beyond the major asperity (TKCH08, 11, 10 and ABSH04 in Fig. 13). 


\section{Discussion and Conclusions}

We have inverted the strong motion and geodetic data for the source process of the 2003 Tokachi-oki, Hokkaido, earthquake and conclude the study with the result of the joint inversion. It indicates that the fault rupture initiated on the upper tip of the 120 by $100 \mathrm{~km}$ fault plane and was developed in the single large asperity generating seismic pulses in the direction of rupture propagation. The obtained slip rate functions around the hypocenter and asperity suggest supershear or near-supershear rupture, which resulted in the distinct directivity effects on ground motions.

Such fast rupture was recovered in the faulting models for the major strike-slip earthquakes, which are the 1979 Imperial Valley earthquake (Archuleta, 1984), the 1992 Landers earthquake (Wald and Heaton, 1994) and the 1999 Izmit earthquake (Bouchon et al., 2000). The 2003 Tokachi-oki earthquake should be the first thrust-faulting event found with this sort of rupture, though our result still includes some uncertainty because of the assumptions on the fault geometry, subfault formulation and crustal structure. Another limitation for studies of this earthquake is that there are no seismic or geodetic stations to the south of the source region.

The simple slip distribution in Fig. 8 is also somewhat unusual for a large earthquake with a magnitude of 8 or greater. However, Yamanaka and Kikuchi (2003) obtained a similar result using teleseismic data, so we can consider the simple distribution with a single major asperity and few minors as a real aspect of this earthquake. It may imply the maturity of the subduction zone in conjunction with the supershear rupture.

Since inverting for fifteen time windows sounds highly over-parameterized, we carried out another joint inversion using ten time windows and a rise time of $2 \mathrm{~s}$. The resultant slip distribution in Fig. 14 retains similar features to those in the previous results, though the major asperity is somewhat intensified. This similarity suggests that our formulation of fifteen time windows works well in cooperation with the spatio-temporal constraints.

Wald and Graves (2001) pointed out the effect of the crustal complexity on the accuracy of geodetic Green's functions, though we assume only the uniform halfspace in this study. This assumption should have introduced some limitations into our results, and so the source model will be refined using 3-D Green's functions in future work.

Acknowledgments. We are grateful to the National Research Institute for Earth Science and Disaster Prevention, Geographical Survey Institute, and JMA for the KiK-net records, GPS data and hypocenter information. The manuscript was greatly improved by the review of Dr. Wald (USGS). We appreciate suggestions by Prof. Archuleta (UC Santa Barbara) on the rupture velocity and geodetic inversion. Figs. 1, 3, 4, 6 and 8 were drawn using the GMT by Drs. Wessel (Univ. Hawaii) and Smith (NOAA) and a shell script by Dr. Yagi (Build. Res. Inst.). This study was partially supported by the Special Coordination Funds for Promoting Science and Technology.

\section{References}

Akaike, H., Likelihood and Bayes procedure, in Bayesian Statistics, edited by J. M. Bernardo et al., pp. 143-166, Univ. Press, Valencia, Spain, 1980.
Aoi, S., K. Obara, S. Hori, K. Kasahara and Y. Okada, New strong-motion observation network: KiK-net, Eos Trans. AGU, 81 (48), Fall Meet. Suppl., Abstract S71A-05, 2000.

Archuleta, R. J., A faulting model for the 1979 Imperial Valley earthquake, J. Geophys. Res., 89, 4559-4585, 1984.

Bouchon, M., N. Toksöz, H. Karabulut, M.-P. Bouin, M. Dietrich, M. Aktar and M. Edie, Seismic imaging of the 1999 Izmit (Turkey) rupture inferred from the near-fault recordings, Geophys. Res. Lett., 27, 3013-3016, 2000.

Earthquake Research Committee, Long-term evaluation of earthquakes along the Kuril trench, http://www.jishin.go.jp/main/chousa/03_mar chishima/index.htm, Headquarters for Earthquake Research Promotion, Tokyo, 2003.

Geographical Survey Institute, Crustal deformation of Japan detected GEONET, http://mekira.gsi.go.jp/ENGLISH/index.html, 1998.

Ide, S., Source process of the 2003 Tokachi-oki earthquake using strong motion and ocean bottom waveforms -Fast rupture exceeds the S-wave velocity?, Prog. Abst. Seismol. Soc. Jpn., TP24, 2003.

Iwasaki, T., H. Shiobara, A. Nishizawa, T. Kanazawa, K. Suyehiro, N. Hirata, T. Urabe and H. Shimamura, A detailed subduction structure in the Kuril trench deduced from ocean bottom seismographic refraction studies, Tectonophys., 165, 315-336, 1989.

JMA, Some reports for the 2003 Tokachi-oki earthquake, http://www.seisvol.kishou.go.jp/eq/2003_09_26_tokachi/index.html, 2003.

Jónsson, S., H. Zebker, P. Segall and F. Amelung, Fault slip distribution of the $1999 M_{\mathrm{w}} 7.1$ Hector Mine, California, earthquake, estimated from satellite radar and GPS measurements, Bull. Seismol. Soc. Am., 92 1377-1389, 2002

Katsumata, K., N. Wada, and M. Kasahara, Newly imaged shape of the deep seismic zone within the subducting Pacific plate beneath the Hokkaido corner, Japan-Kurile arc-arc junction, J. Geophys. Res., 108, 2565 doi:10.1029/2002JB002175, 2003

Kinoshita, S., Kyoshin Net (K-NET), Seismol. Res. Lett., 69, 309-332, 1998.

Kohketsu, K., The extended reflectivity method for synthetic near-field seismograms, J. Phys. Earth, 33, 121-131, 1985.

Koketsu, K., T. Ohno, Y. Ikegami, Rupture process inversion using 3-D Green's functions: the 1995 Kobe earthquake revisited, Eos Trans. AGU, 84(46), Fall Meet. Suppl., Abstract S42H-07, 2003.

Miyazaki, S. and T. Kato, Coseismic slip and afterslip distributions of the 2003 Tokachi-oki earthquake derived from the GEONET data, http://wwweprc.eri.u-tokyo.ac.jp/teru/Tokachi-oki/kato.html, 2003.

Murai, Y., S. Akiyama, K. Katsumata, T. Takanami, T. Yamashina, T. Watanabe, I. Cho, M. Tanaka, A. Kuwano, N. Wada, H. Shimamura, I. Furuya, D. Zhao and R. Sanda, Delamination structure imaged in the source area of the 1982 Urakawa-oki earthquake, Geophys. Res. Lett. 30, 1490, doi:10.1029/2002GL016459, 2003.

NIED, Earthquake mechanism information, http://www.hinet.bosai.go.jp/ topics/miyagi030726/, 2003.

Olson, A. H. and R. J. Apsel, Finite faults and inverse theory with application to the 1979 Imperial Valley earthquake, Bull. Seismol. Soc. Am., 72, 1969-2001, 1982

Rosakis, A. J., O. Samudrala and D. Coker, Cracks faster than the shear wave speed, Science, 284, 1337-1340, 1999.

Wald, D. J. and R. W. Graves, 2001, Resolution analysis of finite fault source inversion using one- and three-dimensional Green's functions 2. Combining seismic and geodetic data, J. Geophys. Res., 106, 8767-8788, 2001.

Wald, D. J. and T. H. Heaton, Spatial and temporal distribution of slip for the 1992 Landers, California, earthquake, Bull. Seismol. Soc. Am., 82, 668-691, 1994.

Yamanaka, Y. and M. Kikuchi, Source process of the recurrent Tokachioki earthquake on September 26, 2003, inferred from teleseismic body waves, Earth Planets Space, e21-e24, 2003.

Yoshida, S., K. Koketsu, B. Shibazaki, T. Sagiya, T. Kato and Y. Yoshida, Joint inversion of near- and far- field waveforms and geodetic data for the rupture process of the 1995 Kobe earthquake, J. Phys. Earth, 44, 437-454, 1996.

Kazuki Koketsu (e-mail: koketsu@eri.u-tokyo.ac.jp) 